\title{
Exploration of risk taking behaviors and perceived susceptibility of colorectal cancer among Malaysian adults: a community based cross-sectional study
}

\author{
Sami AR Al-Dubai ${ }^{*}$, Kurubaran Ganasegeran², Aied M Alabsi ${ }^{3}$, Shamsul A Shah ${ }^{4}$, Farid MM Razali ${ }^{5}$ \\ and John T Arokiasamy ${ }^{1}$
}

\begin{abstract}
Background: Perceived susceptibility to an illness has been shown to affect Health-risk behavior. The objective of the present study was to determine the risk taking behaviors and the demographic predictors of perceived susceptibility to colorectal cancer in a population-based sample.

Methods: A cross-sectional study was carried out among 305 Malaysian adults in six major districts, selected from urban, semi-urban, and rural settings in one state in Malaysia. A self-administered questionnaire was used in this study. It was comprised of socio-demographics, risk-taking behaviors, and validated domains of the Health Belief Model (HBM).

Results: The mean ( \pm SD) age of the respondents was $34.5( \pm 9.6)$ and the majority (59.0\%) of them were 30 years or older. Almost $20.7 \%$ of the respondents felt they were susceptible to colorectal cancer. Self-reported perceived susceptibility mirrored unsatisfactory screening behaviors owing to the lack of doctors' recommendation, ignorance of screening modalities, procrastination, and the perception that screening was unnecessary. Factors significantly associated with perceived susceptibility to colorectal cancer were gender $(\mathrm{OR}=1.8,95 \% \mathrm{Cl}$ 1.0-3.3), age $(\mathrm{OR}=2$. 2, $95 \% \mathrm{Cl} 1.2-4.0)$, ethnicity $(\mathrm{OR}=0.3,95 \% \mathrm{Cl} 0.2-0.6)$, family history of colorectal cancer $(\mathrm{OR}=3.2,95 \% \mathrm{Cl} 1.4-7.4)$ and alcohol intake $(\mathrm{OR}=3.9,95 \% \mathrm{Cl} 2.1-7.5)$.
\end{abstract}

Conclusion: The present study revealed that screening behavior among respondents was unsatisfactory. Hence, awareness of the importance of screening to prevent colorectal cancers is imperative.

Keywords: Behaviors, Colorectal cancer, Health Belief Model, Malaysia, Perceived susceptibility

\section{Background}

Colorectal cancer $(\mathrm{CRC})$ is one of the most common malignancies among adults in both developed and developing countries [1]. Currently, it is the third most commonly diagnosed malignancy and the fourth leading cause of death worldwide [2], with more than 940,000 cases diagnosed annually [3]. Recent reports indicate that it is the fastest emerging gastrointestinal tract cancer in Asia Pacific [4].

\footnotetext{
* Correspondence: samidobaie@yahoo.com

'Department of Community Medicine, International Medical University (IMU), No. 126, Jn Jalil Perkasa 19, Bukit Jalil, 57000 Kuala Lumpur, Malaysia

Full list of author information is available at the end of the article
}

In Malaysia, CRC is the most common malignancy in men and the third commonest malignancy in women (after breast and cervical cancer) [5].

Colorectal cancer is characterized as developing over long periods of time and is a localized and curable condition [6]. The survival rate for localized disease is $90 \%$, compared to less than $10 \%$ for metastatic disease [7]. Screening for CRC has been shown to reduce mortality as it facilitates early detection and prevention of the malignancy [8-10]. The recommended screening methods for early detection of colorectal cancer are fecal occult blood test (FOBT), flexible sigmoidoscopy [11], barium enema and colonoscopy [12].

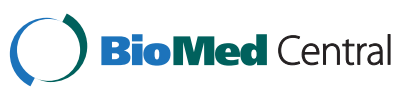


Risk taking behaviors are associated with perceived susceptibility for cancer [13]. Individuals engaged in detrimental health behaviors would perceive a higher susceptibility to malignancies [14]. Smokers were found to perceive a higher susceptibility of developing cancer than nonsmokers $[15,16]$. In a meta-analysis study, a significant association was found between perceived a susceptibility of colorectal cancer and the consumption of fruits and vegetable [17]. Alcohol consumption, obesity and low levels of activity were also reported as risk factors of CRC [18-20].

Social cognitive frameworks in preventive health, namely the Health Belief Model (HBM) [21], the Protection Motivation Theory [22], and the Precaution Adoption Process Model [23] view risk perceptions with perceived susceptibility as a catalyst for primary prevention [24]. Perceived susceptibility advocates the "motivational engine" for precautionary behaviors [13]. However, social cognitive critics debate the validity of variables from these models, which tend to predict behavioral intention rather than the behavior itself [25]. McQueen et al., (2010) posed the alternate hypothesis that perceived susceptibility advocates change in psychosocial predictors influencing subsequent intentions and behavior [26]. The HBM relates a socio-psychological theory of decision making to the individual health-related behaviors and it included four dimensions: Susceptibility, Severity, Benefits and Costs [21]. This study believes that understanding the determinants of perceived susceptibility to colorectal cancer is a crucial element in constructing cancer preventive health behaviors.

This study aims to explore risk taking behaviors and perceived susceptibility to colorectal cancer among healthy communities from different geographical settings (urban, semi-urban and rural) and ages. This study will overcome gaps and weaknesses of previous studies by expanding its socio-demographic factors and other relevant covariates concerning colorectal cancer susceptibility and screening behaviors by using the validated Health Belief Model (HBM) [21] among the Malaysian population.

\section{Methods}

\section{Study setting and population}

A community-based cross-sectional study was conducted in three different geographical settings (urban, semiurban, and rural areas) within the state of Selangor, Malaysia. This state includes six major districts, namely Subang Jaya, Petaling Jaya, Selayang, Klang, Kuala Selangor and Kuala Langat. Subang Jaya and Petaling Jaya are urban settings, Selayang and Klang are semi-urban, and Kuala Selangor and Kuala Langat are rural. The sample size required for this study was estimated to be 280 respondents. This calculation was based on previous study parameters [27] using Lwanga and Lemeshow's equation (1991). We added $10 \%$ of the calculated sample size (28) to compensate for missing data or non-response and so the sample size rose to 308 . Respondents aged $\geq 18$ years, and who lived for at least one year in these districts, were also included in this study. Respondents were approached at various commercial settings and major streets within the selected residential areas using convenience sampling. Questionnaires were administered in both English and the local language.

\section{Ethical consideration}

The purpose of the study was explained to respondents. Confidentiality and their right to withdraw were ensured. Participants received a written description of the purpose and aims of the study along with the study questionnaires and participant consent was obtained. Approval was obtained from the ethics committee of the International Medical School in the Management and Science University (MSU), Malaysia.

\section{Study instruments}

A self-administered questionnaire was developed using previous literatures and the validated Health Belief Model Scale (HBM) for colorectal cancer [21]. Socio-demographics included 10 questions relating to gender, age, race, residency area, marital status, level of education, occupation, family income, family history of any cancer, and family history of colorectal cancer. We designed a fiveitem mini-subscale to assess the risk taking behaviors of colorectal cancer (smoking, alcohol intake, fruits and vegetable consumption, exercise and obesity). The Body Mass Index (BMI) was calculated as weight in kilograms divided by height in square meters $(\mathrm{kg} / \mathrm{m} 2)$. This study adopted the World Health Organisation's (WHO) BMI cut-off points for Asian populations. A BMI $<18.5 \mathrm{~kg} / \mathrm{m}^{2}$ was categorized as underweight, $18 \cdot 5-22 \cdot 9 \mathrm{~kg} / \mathrm{m}^{2}$ as normal and $\geq 23.0 \mathrm{~kg} / \mathrm{m}^{2}$ as overweight. The latter was further classified as pre-obese $\left(23.0-27.4 \mathrm{~kg} / \mathrm{m}^{2}\right)$, obese Class I $\left(27.5-34.9 \mathrm{~kg} / \mathrm{m}^{2}\right)$, obese Class II $\left(35.0-39.9 \mathrm{~kg} / \mathrm{m}^{2}\right)$, and obese Class III $\left(\geq 40 \mathrm{~kg} / \mathrm{m}^{2}\right)$ [28]. To ease analysis "underweight" and "normal range" were categorized as 'normal' while "pre-obese" and "obese Class I, II and III" were categorized as 'obese'. The validated HBM was used in this study. It assessed four main constructs namely: perceived susceptibility ( 1 item), perceived severity ( 1 item), perceived benefits ( 1 item) and perceived barriers (17 items) [21]. Response options include "Agree" or "Disagree". the questionnaire was pilot-tested among 10 respondents.

\section{Statistical analyses}

Data analysis was performed using the Statistical Package of Social Sciences (SPSS) software, version 16.0. Descriptive statistics were obtained for all variables in the study. The chi-square test was used to assess the association between perceived susceptibility and categorical variables in 
this study. For variables with three or more categories, simple logistic regression analysis was used to obtain the odds ratio (OR). Multiple logistic regression analysis using the Backward Wald technique was performed to obtain factors associated with perceived susceptibility to colorectal cancer. All independent variables that had significant associations with perceived susceptibility in bivariate analysis were included in the multivariate analysis. Multi-collinearity between independent variables was checked for by the values of standard errors (SE).

Table 1 Socio -demographic characteristics of respondents $(n=305)$

\begin{tabular}{|c|c|c|}
\hline Characteristics & $\mathbf{N}$ & $\%$ \\
\hline \multicolumn{3}{|l|}{ Gender } \\
\hline Male & 185 & 60. \\
\hline Female & 120 & 39. \\
\hline \multicolumn{3}{|l|}{ Age } \\
\hline$\leq 30$ years & 125 & 41. \\
\hline$>30$ years & 180 & 59 \\
\hline \multicolumn{3}{|l|}{ Race } \\
\hline Malay & 185 & 60. \\
\hline Chinese & 74 & 24 \\
\hline Indian & 46 & 15. \\
\hline \multicolumn{3}{|l|}{ Residency } \\
\hline Urban & 105 & 34. \\
\hline Semi-urban & 100 & 32. \\
\hline Rural & 100 & 32 \\
\hline \multicolumn{3}{|l|}{ Marital status } \\
\hline Married & 176 & 57. \\
\hline Unmarried & 129 & 42. \\
\hline \multicolumn{3}{|l|}{ Education level } \\
\hline High school or less & 151 & 49. \\
\hline College/University & 154 & 50 \\
\hline \multicolumn{3}{|l|}{ Occupation } \\
\hline Employed & 279 & 91. \\
\hline Unemployed & 26 & 8.5 \\
\hline \multicolumn{3}{|c|}{ Family income (MYR) /month* } \\
\hline$<3000$ & 178 & 58 \\
\hline $3000-5000$ & 85 & 27. \\
\hline$>5000$ & 42 & 13.8 \\
\hline \multicolumn{3}{|c|}{ Family history of any cancer } \\
\hline Yes & 32 & 10 \\
\hline No & 273 & 89. \\
\hline \multicolumn{3}{|c|}{ Family history of colorectal cancer } \\
\hline Yes & 26 & 8.5 \\
\hline No & 279 & 91.5 \\
\hline
\end{tabular}

The accepted level of significance in this study was set below $0.05(\mathrm{p}<0.05)$.

\section{Results}

Socio-demographic characteristics of the respondents

The data of 305 respondents were included in the analysis (three questionnaires were excluded due to missing data). The mean $( \pm \mathrm{SD})$ age of respondents was $34.5( \pm 9.6)$ years with the majority aged 30 years or older $(59.0 \%)$. One hundred eighty five were Malays (60.7\%), 175 were married $(57.7 \%), 154$ were tertiary educated $(50.5 \%), 278$ were currently employed (91.5\%), 26 respondents (8.5\%) had a family history of colorectal cancer and 32 (10.5\%) had a family history of other malignancies (Table 1 ).

\section{Risk taking behaviors of colorectal cancer among respondents}

Table 2 exhibits the respondents' risk taking behaviors regarding colorectal cancer. One hundred eighty three were obese $(60.0 \%), 75$ (24.6\%) consumed fruits and vegetables less than three times per week, 74 (24.3\%) and $51(16.7 \%)$ respondents respectively reported cigarette smoking and drinking alcohol, while 264 (13.4\%) reported performing exercise less than three times per week.

\section{Perception of colorectal cancer and screening according to Health Belief Model}

Two hundred and twenty two of the respondents (79.3\%) believed that the risk of getting colorectal cancer was low, 231 (75.7\%) believed that colorectal cancer is serious if diagnosed late and $237(77.7 \%)$ of respondents were

Table 2 Risk taking behaviors of colorectal cancer among respondents $(n=305)$

\begin{tabular}{lcc}
\hline Risky behaviors & N & \% \\
\hline Smoking & 74 & \\
Yes & 231 & 75.3 \\
No & & \\
Drinking alcohol & 51 & 16.7 \\
Yes & 254 & 83.3 \\
No & & \\
Exercise & 41 & 13.4 \\
$<3$ times per week & 264 & 86.6 \\
$\geq 3$ times per week & & \\
Consuming fruits \& vegetable & 75 & 24.6 \\
$<3$ times per week & 230 & 75.4 \\
$\geq 3$ times per week & & \\
Obesity & 183 & 60.0 \\
Obese & 122 & 40.0 \\
Normal &
\end{tabular}


not worried about discovering colorectal cancer if they had screening tests. In addition, 169 participants (55.4\%) reported that they did not have an FOBT because it was "not recommended by a doctor". Similarly, 153 (50.2\%) respondents reported the same reason for not having a flexible sigmoidoscopy. Other stated reasons are shown in Table 3.

\section{Perceived susceptibility to colorectal cancer by socio-demographic characteristics}

Table 4 shows the association between socio-demographic factors and perceived susceptibility to colorectal cancer. Perceived susceptibility was higher in men compared to women $(\mathrm{OR}=1.8,95 \% \mathrm{CI} 1.0-3.3, \mathrm{p}=0.045)$, and in those aged $>30$ years compared to younger respondents
$(\mathrm{OR}=2.2,95 \%$ CI 1.2-4.0, $\mathrm{p}=0.011)$. Perceived susceptibility was lower among Malays and Indians when compared with Chinese $(\mathrm{OR}=0.3,95 \% \mathrm{CI} 0.2-0.6, \mathrm{p}=0.001)$, (OR $=0.3,95 \%$ CI 0.1-0.7, $\mathrm{p}=0.007$ respectively). Respondents with a family history of colorectal cancer perceived a higher susceptibility in comparison to those without $(\mathrm{OR}=3.2,95 \%$ CI 1.4-7.4, $\mathrm{p}=0.004)$.

\section{Association between risk taking behaviors and perceived susceptibility to colorectal cancer}

Table 5 shows the association between risk taking behaviors and perceived susceptibility to colorectal cancer. Alcohol consumption was the only risk taking behavior that had a significant association with perceived susceptibility $(\mathrm{OR}=3.9,95 \%$ CI $2.1-7.5 \mathrm{p}<0.001)$.

Table 3 Perception of colorectal cancer and screening among respondents $(n=305)$

\begin{tabular}{|c|c|c|}
\hline Statement & $\begin{array}{l}\text { Agree } \\
\mathrm{N}(\%)\end{array}$ & $\begin{array}{c}\text { Disagree } \\
\text { N (\%) }\end{array}$ \\
\hline \multicolumn{3}{|l|}{ Perceived susceptibility } \\
\hline My chance of getting colorectal cancer is great & $63(20.7)$ & $242(79.3)$ \\
\hline \multicolumn{3}{|l|}{ Perceived severity } \\
\hline Colorectal cancer may be serious if it is found late & $231(75.7)$ & $74(24.3)$ \\
\hline \multicolumn{3}{|l|}{ Perceived benefits } \\
\hline If I have colorectal cancer, I will have a good chance of survival if the cancer is found early & $204(66.9)$ & $101(33.1)$ \\
\hline \multicolumn{3}{|l|}{ Perceived barriers } \\
\hline \multicolumn{3}{|l|}{ Reasons for not getting FOBT } \\
\hline Procrastination & $113(37.0)$ & $192(63.0)$ \\
\hline Didn't know I should have it & $120(39.3)$ & $185(60.7)$ \\
\hline Do not think it's necessary & $71(23.3)$ & $234(76.7)$ \\
\hline Not recommended by my doctor & $169(55.4)$ & $136(44.6)$ \\
\hline Too embarrassing & $55(18.0)$ & $250(82.0)$ \\
\hline I don't have health problems & $127(41.6)$ & $178(58.4)$ \\
\hline \multicolumn{3}{|l|}{ Concerns about FOBT } \\
\hline Worried that FOBT is messy & $75(24.6)$ & $230(75.4)$ \\
\hline Worried that FOBT is inconvenient & $95(31.1)$ & $210(68.9)$ \\
\hline \multicolumn{3}{|l|}{ Reasons for not getting FlexibleSigmoidoscopy } \\
\hline Procrastination & $115(37.7)$ & $190(62.3)$ \\
\hline I don't know I should have it & $118(38.7)$ & $187(61.3)$ \\
\hline I don't think it's necessary & $87(28.5)$ & $218(71.5)$ \\
\hline It was not recommended by my doctor & $153(50.2)$ & $152(49.8)$ \\
\hline I have no symptoms & $132(43.3)$ & $173(56.7)$ \\
\hline It is painful & $82(26.9)$ & $223(73.1)$ \\
\hline \multicolumn{3}{|l|}{ Concerns about Flexible Sigmoidoscopy } \\
\hline Worried that Flexible Sigmoidoscopy is embarrassing & $96(31.5)$ & $209(68.5)$ \\
\hline Worried that Flexible Sigmoidoscopy is painful & $91(29.8)$ & $214(70.2)$ \\
\hline \multicolumn{3}{|l|}{ Perceived barriers to CRC screening } \\
\hline Fear of discovering cancer & $68(22.3)$ & $237(77.7)$ \\
\hline
\end{tabular}


Table 4 Association between perceived susceptibility of colorectal cancer and demographic variables $(n=305)$

\begin{tabular}{|c|c|c|c|c|c|}
\hline Characteristics & $\begin{array}{c}\text { Perceived higher chance of } \\
\text { having colorectal cancer } \\
\mathrm{N}(\%)\end{array}$ & $\begin{array}{l}\text { Perceived lower chance of } \\
\text { having colorectal cancer } \\
\mathrm{N}(\%)\end{array}$ & OR & $95 \% \mathrm{Cl}$ & P-value \\
\hline \multicolumn{6}{|l|}{ Gender } \\
\hline Male & $45(24.3)$ & $140(75.7)$ & 1.8 & $1.0-3.3$ & 0.045 \\
\hline Female & $18(15.0)$ & $102(85.0)$ & 1 & & \\
\hline \multicolumn{6}{|l|}{ Age } \\
\hline$\leq 30$ years & 17 (13.6) & $108(86.4)$ & 1 & & \\
\hline$>30$ years & $46(25.6)$ & $134(74.4)$ & 2.2 & $1.2-4.0$ & 0.011 \\
\hline \multicolumn{6}{|l|}{ Race* } \\
\hline Malay & $30(16.2)$ & $155(83.8)$ & 0.3 & $0.2-0.6$ & 0.001 \\
\hline Indian & $6(13.0)$ & $40(87.0)$ & 0.3 & $0.1-0.7$ & 0.007 \\
\hline Chinese & $27(36.5)$ & $47(63.5)$ & 1 & & \\
\hline \multicolumn{6}{|l|}{ Residency* } \\
\hline Urban & $29(27.6)$ & $76(72.4)$ & 1 & & \\
\hline Semi-urban & $17(17.0)$ & $83(83.0)$ & 0.5 & $0.3-1.1$ & 0.071 \\
\hline Rural & $17(17.0)$ & $83(83.0)$ & 0.5 & $0.3-1.1$ & 0.071 \\
\hline \multicolumn{6}{|l|}{ Marital status } \\
\hline Married & $42(23.9)$ & $134(76.1)$ & 1.6 & $0.9-2.9$ & 0.106 \\
\hline Unmarried & $21(16.3)$ & $108(83.7)$ & 1 & & \\
\hline \multicolumn{6}{|l|}{ Education level } \\
\hline High school or less & $30(47.6)$ & $124(51.2)$ & 1 & & \\
\hline College/University & $33(52.4)$ & $118(48.8)$ & 1.2 & $0.7-2.0$ & 0.609 \\
\hline \multicolumn{6}{|l|}{ Occupation } \\
\hline Employed & $57(20.4)$ & $222(79.6)$ & 1 & & \\
\hline Unemployed & $6(23.1)$ & $20(76.9)$ & 1.2 & $0.4-3.0$ & 0.750 \\
\hline \multicolumn{6}{|c|}{ Family income (MYR)* } \\
\hline$<3000$ & $33(18.5)$ & $145(81.5)$ & 1 & & \\
\hline $3000-5000$ & $21(24.7)$ & $64(75.3)$ & 1.4 & $0.8-2.7$ & 0.248 \\
\hline$>5000$ & $9(21.4)$ & $33(78.6)$ & 1.2 & $0.5-2.7$ & 0.669 \\
\hline \multicolumn{6}{|c|}{ Family history of any cancer } \\
\hline Yes & $53(19.4)$ & $220(80.6)$ & 1 & & \\
\hline No & $10(31.2)$ & $22(68.8)$ & 1.9 & $0.8-4.2$ & 0.122 \\
\hline \multicolumn{6}{|c|}{ Family history of colorectal cancer } \\
\hline Yes & $11(42.3)$ & $15(57.7)$ & 3.2 & $1.4-7.4$ & 0.004 \\
\hline No & $52(18.6)$ & $227(81.4)$ & 1 & & \\
\hline
\end{tabular}

* Simple logistic regression was used to obtain the OR.

Factors associated with perceived susceptibility among respondents in multiple logistic regression analysis In the multiple logistic regression analysis, age and race were significantly associated with perceived susceptibility to colorectal cancer. Respondents aged $>30$ years were more likely to report that they were susceptible to colorectal cancer compared to those aged $\leq 30$ years $(\mathrm{OR}=2.6$, 95\% CI 1.4-4.9). A Malay (OR $=95 \%$ CI 0.2-0.6) or Indian
$(\mathrm{OR}=0.2,95 \%$ CI $0.1-0.7)$ was less likely to report that they were susceptible to cancer compared to Chinese (Table 6).

\section{Discussion}

This study aimed to explore risk taking behaviors and determine potential factors affecting perceived susceptibility to colorectal cancer among the Malaysian population. Of the 305 respondents surveyed, 20.7\% perceived 
Table 5 Association between risk taking behaviors and perceived susceptibility among respondents $(n=305)$

\begin{tabular}{|c|c|c|c|c|c|}
\hline \multirow[t]{3}{*}{ Characteristics } & \multicolumn{2}{|c|}{ Believe chance of having colorectal cancer is high } & \multirow[t]{3}{*}{$O R^{*}$} & \multirow[t]{3}{*}{$95 \% \mathrm{Cl}$} & \multirow[t]{3}{*}{ P-value } \\
\hline & Yes & No & & & \\
\hline & N (\%) & $\mathrm{N}(\%)$ & & & \\
\hline \multicolumn{6}{|l|}{ Smoking } \\
\hline Yes & $18(28.6)$ & $56(23.1)$ & \multirow{2}{*}{1.3} & \multirow{2}{*}{$0.7-2.5$} & \multirow{2}{*}{0.370} \\
\hline No & $45(71.4)$ & $186(76.9)$ & & & \\
\hline \multicolumn{6}{|l|}{ Alcohol } \\
\hline Yes & $22(34.9)$ & $29(12.0)$ & \multirow{2}{*}{3.9} & \multirow{2}{*}{$2.1-7.5$} & \multirow{2}{*}{$<0.001$} \\
\hline No & $41(65.1)$ & $213(88.0)$ & & & \\
\hline \multicolumn{6}{|l|}{ Exercise } \\
\hline Less than three times per week & $7(11.1)$ & $34(14.0)$ & \multirow{2}{*}{0.8} & \multirow{2}{*}{$0.3-1.8$} & \multirow{2}{*}{0.542} \\
\hline Three or more times per week & $56(88.9)$ & $208(86.0)$ & & & \\
\hline \multicolumn{6}{|l|}{ Consume fruits and vegetable } \\
\hline Less than three times per week & $17(27.0)$ & $58(24.0)$ & \multirow{2}{*}{1.2} & \multirow{2}{*}{$0.6-2.2$} & \multirow{2}{*}{0.620} \\
\hline Three or more times per week & $46(73.0)$ & $184(76.0)$ & & & \\
\hline \multicolumn{6}{|l|}{ Body Mass Index (BMI) } \\
\hline Obese & $28(44.4)$ & $94(38.8)$ & \multirow{2}{*}{1.3} & \multirow{2}{*}{$0.7-2.2$} & \multirow{2}{*}{0.419} \\
\hline Normal & $35(55.6)$ & $148(61.2)$ & & & \\
\hline
\end{tabular}

high chances of having colorectal cancer. In the final model, age and race were significantly associated with perceived susceptibility to colorectal cancer.

To the best of our knowledge, this study was the first Malaysian study to assess self-reported risk-taking behaviour and perceived susceptibility to colorectal cancer. The estimated rate of perceived susceptibility reported in the present study was comparatively higher to that found in a British sample (17\%) [14] but relatively lower than that reported from the United States of America (USA) (29-50\%) [29-31].

Health behavioral theories predicted higher intentions of preventive actions among individuals with greater susceptibility to a disease $[13,32]$. However, in the present

\begin{tabular}{|c|c|c|c|c|c|c|}
\hline Predictors & B & SE & Wald & $\operatorname{Exp}(B)$ & $95 \% \mathrm{Cl}$ & $P$ value \\
\hline \multicolumn{7}{|l|}{ Age } \\
\hline$\leq 30$ years & Ref & Ref & Ref & Ref & Ref & Ref \\
\hline$>30$ years & 0.940 & 0.327 & 8.269 & 2.6 & $1.4-4.9$ & 0.004 \\
\hline \multicolumn{7}{|l|}{ Race } \\
\hline Malay & -1.236 & 0.325 & 14.430 & 0.3 & $0.2-0.6$ & $<0.001$ \\
\hline Indian & -1.419 & 0.509 & 7.782 & 0.2 & $0.1-0.7$ & 0.005 \\
\hline Chinese & Ref & Ref & Ref & Ref & Ref & Ref \\
\hline
\end{tabular}

Variables entered: Gender, age, race, residency, marital status, family history of any cancer and family history of colorectal cancer. $\operatorname{Exp}(B)$ gives the Odds Ratio. study, self-reported susceptibility mirrored unsatisfactory preventive behaviours. The barriers to screening for colorectal cancer in this study were consistent with previous studies from Malaysia on the barriers of CRC screening [33] and USA [8,34].

In the present study, perceived susceptibility to colorectal cancer was significantly higher among men. A previous study by Wardle et al., (2005) [35] found that men had low perceived susceptibility while some studies found no relationship between gender and perceived susceptibility [36-38]. Our study's findings on the association between perceived susceptibility and age was consistent with previous studies $[14,39]$.

A new finding in this study was the significant association between perceived susceptibility and race. Despite the high incidence of colorectal cancer among ethnic Chinese in Malaysia [33], this study found higher perceived susceptibility among ethnic Malays and Indians in comparison to Chinese. A possible explanation could be due to a lack of information among respondents. In the literature, the association between ethnicity and perceived susceptibility was masked. A study by Shokar et al., (1990) concluded that whites were more likely to contract colorectal cancer than blacks.

This study found a significant relationship between perceived susceptibility and family history of colorectal cancer which was consistent with previous studies $[13,29,31,40]$.

This study also found a significant association between alcohol intake and the perceived susceptibility to 
colorectal cancer which was, again, consistent with a previous study [41]. Our finding of the relationship between smoking and perceived susceptibility was inconsistent with some previous studies $[15,16]$. Although some longitudinal studies had observed a positive relationship between perceived risk and subsequent behaviour, that association was weak and unsatisfactory. Some studies, however, find no association or even a negative one [32,42].

The cross-sectional design of the current study can test the "accuracy hypothesis" that asserts that perceptions of risk at a certain time properly reflect one's risk behaviours at that time [41]. Thus, this design can be useful for identifying information deficits and the areas where further education is needed. The failure of the current study to find an association between the perceived susceptibility and risk taking behaviors could be attributed to the natural causal relationship between those variables in which the cross-sectional design was not appropriate [41]. A second possible reason could be due to an inadequate specification of the links between perceived susceptibility and risk taking behaviour in the study questionnaire. In other words, our respondents may not answer the "perceived susceptibility" questions according to their awareness that smoking is a risk for developing cancer. To avoid such bias in the future, this study recommends phrasing the question in another way, for example, "If you don't change your smoking behaviour, what is your chance of getting colorectal cancer in the future?" By using such a question, we can link the perceived susceptibility to the behaviour. An alternative way is to assess the relationship between the perceived susceptibility and the intention to quit or stop the risky behaviours. Although intentions may not necessarily predict or reflect the actual behaviours, it could be considered as an intermediate step towards action.

The cross-sectional nature of this study could not establish the causal relationships between perceived susceptibility and behaviour. Thus, further exploration is required through prospective and meta-analysis studies.

\section{Conclusions}

This study found unsatisfactory screening behaviors due to the lack of doctors' recommendation, unawareness of screening modalities, procrastination, and a negative apprehension that screening was unnecessary. Perceived susceptibility was associated significantly with age, race, and alcohol intake. Community health education and a health promotion program of colorectal cancer risk factors and screening methods should be conducted among the community. Doctors and health care providers should be engaged in public education.

\section{Competing interests}

The authors declare that they do not have competing interests.

\section{Authors' contributions}

SAR and KG designed the research protocol. MFMR conducted data collection, data cleaning and normality check. SAR, SAS and AMA conducted data analyses and interpretation. KG, SAR and MFMR wrote the paper. SAS, JTA and, SAR revised the final draft critically for important intellectual content. All authors read and approved the final manuscript.

\section{Author details}

'Department of Community Medicine, International Medical University (IMU), No. 126, Jln Jalil Perkasa 19, Bukit Jalil, 57000 Kuala Lumpur, Malaysia. ${ }^{2}$ International Medical School, Management and Science University (MSU), University Drive, Off Persiaran Olahraga, Section 13, 40100 Shah Alam, Selangor, Malaysia. ${ }^{3}$ Oral Cancer Research And Coordinating Center, Faculty of Dentistry, University of Malaya (UM), Kuala Lumpur 50603 Malaysia. ${ }^{4}$ Department of Community Health, UKM Medical Centre, Jalan Yaacob Latif, Bandar Tun Razak, Cheras, 56000 Kuala Lumpur, Malaysia. ${ }^{5}$ Perdana University Graduate School of Medicine, Perdana University, Maeps Building, Mardi Complex, 43400 Serdang, SelangorMalaysia.

Received: 28 March 2013 Accepted: 2 October 2013

Published: 7 October 2013

\section{References}

1. Jemal A, Bray F, Center MM, Ferlay J, Ward E, Forman D: Global cancer statistics. CA Cancer J Clin 2011, 61(2):69-90.

2. Salimzadeh $\mathrm{H}$, Delavari A, Montazeri A, Mirzazadeh A: Knowledge and practice of Iranians towards colorectal cancer, and barriers to screening. Int J Prev Med 2012, 3:29-35.

3. Siegel R, Ward E, Brawley O, Jemal A: Cancer statistics, 2011. CA Cancer J Clin 2011, 61(4):212-236.

4. Sung JJ, Choi SY, Chan FK, Ching JY, Lau JT, Griffiths S: Obstacles to colorectal cancer screening in Chinese: a study based on the health belief model. Am J Gastroenterol 2005, 103:974-981.

5. Lim GCC, Rampal S, Halimah Y: Cancer Incidence in Peninsular Malaysia 20032005, National Cancer Registry Kuala Lumpur. 2008. http://www.moh.gov.my/ images/gallery/Report/Cancer/CancerlncidenceinPeninsularMalaysia20032005x1x.pdf.

6. Young G, Rozen P, Levin B: How does colorectal cancer develop? Colorectal cancer in clinical practice: prevention, early detection and management. Abingdon: Taylor and Francis 2006, 2:27-46

7. Jemal A, Siegel R, Ward E, Hao Y, Xu J, Murray T, Thun MJ: Cancer statistics. CA Cancer J Clin 2008, 58(2):71-96.

8. Dolan NC, Ferreira MR, Davis TC, Fitzgibbon ML, Rademaker A, Liu D, Schmitt BP, Gorby N, Wolf M, Bennett CL: Colorectal cancer screening knowledge, attitudes, and beliefs among veterans: does literacy make a difference? JCO 2004, 22(13):2617-2622.

9. Steele RJ, McClements PL, Libby G, Black R, Morton C, Birrel J, Mowat NAG: Results from the first three rounds of the Scottish demonstration pilot of FOBT screening for colorectal cancer. Gut 2009, 58:530-535.

10. Atkin WS, Edwards R, Kralj-Hans I, Wooldrage K, Hart AR, Northover J, Parkin DM, Wardle J, Duffy SW, Cuzick J: Once-only flexible sigmoidoscopy screening in prevention of colorectal cancer: a multicentre randomised controlled trial. Lancet 2010, 375(9726):1624-1633.

11. Zauber AG, Winawer SJ, O'Brien MJ, Lansdorp-Vogelaar I, van Ballegooijen M, Hankey BF, Shi W, Bond JH, Schapiro M, Panish JF: Colonoscopic polypectomy and long-term prevention of colorectal-cancer deaths. N Engl J Med 2012, 366(8):687-696.

12. Ford JS, Coups EJ, Hay JL: Knowledge of colon cancer screening in a national probability sample in the United States. J Health Commun 2006, 11:19-35.

13. Robb KA, Miles A, Wardle J: Perceived risk of colorectal cancer: sources of risk judgements. Cancer Epidemiol Biomarkers Prev 2007, 16:694-702.

14. Robb KA, Miles A, Wardle J: Demographic and psychosocial factors associated with perceived risk for colorectal cancer. Cancer Epidemiol Biomarkers Prev 2004, 13:366-372.

15. Bleiker E, Menko FH, Taal BG, Kluijt I, Wever LD, Gerritsma MA, Vasen HF, Aaronson NK: Screening behavior of individuals at high risk for colorectal cancer. Gastroenterology 2005, 128(2):280-287.

16. Green AR, Betancourt JR, Richter JM, Janairo M-PR, Gamba GB, Atlas SJ: Barriers to screening colonoscopy for low-income Latino and white patients in an urban community health center. J Gen Intern Med 2008, 23(6):834-840 
17. Aune D, Chan DS, Lau R, Vieira R, Greenwood DC, Kampman E, Norat T: Dietary fibre, whole grains, and risk of colorectal cancer: systematic review and dose-response meta-analysis of prospective studies. BMJ 2011 343:d6617.

18. Huxley HA, Clifton P, Czernichow S, Parr CL, Woodward M: The impact of dietary and lifestyle risk factors on risk of colorectal cancer: A quantitative overview of the epidemiological evidence. Int J Cancer 2009, 125:171-180.

19. Pelucchi C, Tramacere I, Boffetta P, Negri E, La Vecchia C: Alcohol consumption and cancer risk. Nutr Cancer 2011, 63:983-990.

20. Parkin DM, Boyd L, Walker LC: The fraction of cancer attributable to lifestyle and environmental factors in the UK in 2010. Br J Cancer 2011, 105(Suppl 2):77-81.

21. Rosenstock IM: Historical origins of the health belief model. Health Educ Monogr 1974, 2:1-8.

22. Rogers RW: A protection motivation theory of fear appeals and attitude change. J Psychol 1975, 91:93-114.

23. Weinstein ND: The precaution adoption process. Health Psychol 1988, 7:355-386.

24. Gregory TA, Wilson C, Duncan A, Turnbull D, Cole SR, Young G: Demographic, social cognitive and social ecological predictors of intention and participation in screening for colorectal cancer. BMC Public Health 2011, 11:38. doi:10.1186/1471-2458-11-38.

25. Armitage $C J$, Conner M: Social cognitive models and health behaviour: a structured review. Psychol and Health 2000, 15:173-189.

26. McQueen A, Vernon SW, Rothman AJ, Norman GJ, Myers RE, Tilley BC Examining the role of perceived susceptibility on colorectal cancer screening intention and behavior. Ann Behav Med 2010, 40:205-217. doi:10.1007/s12160-010-9215-3.

27. Lwanga SK, Lemeshow S: Sample Size Determination in Health Studies: A Practical Manual. Geneva: World Health Organization; 1991.

28. WHO Expert Consultation: Appropriate body-mass index for Asian populations and its implications for policy and intervention strategies. Lancet 2004, 363:157-163.

29. Shokar NK, Carlson CA, Weller SC: Factors associated with racial/ethnic differences in colorectal cancer screening. Am Board Family Med 2008, 21(5):414-426.

30. Lipkus IM, Rimer BK, Lyna PR, Pradhan AA, Conaway M, Woods-Powell CT: Colorectal screening patterns and perceptions of risk among AfricanAmerican users of a community health center. J Commun Health 1996, 21:409-427.

31. Aiken LS, Fenaughty AM, West SG, Johnson JJ, Luckett TL: Perceived determinants of risk for breast cancer and the relations among objective risk, perceived risk, and screening behavior over time. Women Health 1995, 1:27-50.

32. Vollrath M, Knoch D, Cassano L: Personality, risky health behaviour and perceived susceptibility to health risks. Eur J Pers 1999, 13:39-50.

33. Hilmi I, Hartono JL, Goh K: Negative perception in those at highest riskpotential challenges in colorectal cancer screening in an urban Asian population. Asian Pac J Cancer Prev 2010, 11:815-822.

34. Rawl SM, Menon U, Champion VL, May FE, Loehrer P Sr, Hunter C, Azzouz F, Monahan PO, Skinner CS: Do benefits and barriers differ by stage of adoption for colorectal cancer screening? Health Educ Res 2005, 20(2):137-148. doi:10.1093/her/cyg110.

35. Wardle J, Miles A, Atkin W: Gender differences in utilization of colorectal cancer screening. Med Screen 2005, 12:20-27.

36. Courtenay WH, McCreary DR, Merighi JR: Gender and ethnic differences in health beliefs and behaviours. J Health Psychol 2002, 7:219-231.

37. Lipkus IM, Klein WMP: Effects of communicating social comparison information on risk perceptions for colorectal cancer. $J$ Health Commun 2006, 11:391-407.

38. Domanska K, Nilbert M, Soller M, Silfverberg B, Carlsson C: Discrepancies between estimated and perceived risk of cancer among individuals with hereditary nonpolyposis colorectal cancer. Genet Test 2007, 11(2):183-186.

39. Codori AM, Waldeck T, Petersen GM, Miglioretti D, Trimbath JD, Tillery MA: Genetic counseling outcomes: perceived risk and distress after counseling for hereditary colorectal cancer. J Genet Couns 2005, 14(2):119-132.

40. Tilburt JC, James KM, Sinicrope PS, Eton DT, Costello BA, Carey J, Lane MA, Ehlers SL, Erwin PJ, Nowakowski KE, Murad MH: Factors influencing cancer risk perception in high risk population: a systemic review. Hereditary Cancer in Clin Pract 2011, 9:2. doi:10.1186/1897-4287-9-2.
41. Fedirko V, Tramacere I, Bagnardi V, Rota M, Scotti L, Islami F, Negri E, Straif K, Romieu I, La Vecchia C: Alcohol drinking and colorectal cancer risk: an overall and dose-response meta-analysis of published studies. Ann Oncol 2011, 22(9):1958-1972.

42. Brewer NT, Weinstein ND, Cuite CL, Herrington JE: Risk perceptions and their relation to risk behavior. Ann Behav Med 2004, 27(2):125-130.

doi:10.1186/1471-2458-13-930

Cite this article as: Al-Dubai et al:: Exploration of risk taking behaviors and perceived susceptibility of colorectal cancer among Malaysian adults: a community based cross-sectional study. BMC Public Health 2013 13:930.

\section{Submit your next manuscript to BioMed Central and take full advantage of:}

- Convenient online submission

- Thorough peer review

- No space constraints or color figure charges

- Immediate publication on acceptance

- Inclusion in PubMed, CAS, Scopus and Google Scholar

- Research which is freely available for redistribution 